\title{
Article \\ The Power of Combining MA-XRF, Infrared Reflectography and Digital Microscopy to Unveil the Production of the 16th Century Illuminated Charter of Évora: What May Be Hidden under a Painted Surface?
}

\author{
Catarina Miguel ${ }^{1,2, *}$, Silvia Bottura-Scardina ${ }^{3} \mathbb{D}$, Carlo Bottaini ${ }^{1,2} \mathbb{D}$, Sara Valadas ${ }^{1,2} \mathbb{D}$, Antonio Candeias ${ }^{1,2}$ \\ and Francisco Bilou 4
}

check for updates

Citation: Miguel, $\mathrm{C}$. Bottura-Scardina, S.; Bottaini, C.; Valadas, S.; Candeias, A.; Bilou, F. The Power of Combining MA-XRF, Infrared Reflectography and Digital Microscopy to Unveil the Production of the 16th Century Illuminated Charter of Évora: What May Be Hidden under a Painted

Surface? Heritage 2022, 5, 286-296.

https://doi.org/10.3390/

heritage 5010015

Academic Editor:

Francesco Soldovieri

Received: 27 December 2021

Accepted: 21 January 2022

Published: 26 January 2022

Publisher's Note: MDPI stays neutral with regard to jurisdictional claims in published maps and institutional affiliations.

Copyright: (C) 2022 by the authors. Licensee MDPI, Basel, Switzerland. This article is an open access article distributed under the terms and conditions of the Creative Commons Attribution (CC BY) license (https:// creativecommons.org/licenses/by/ $4.0 /)$
1 HERCULES Laboratory, Institute for Advanced Studies and Research, University of Evora, 7000-809 Evora, Portugal; carlo@uevora.pt (C.B.); svaladas@uevora.pt (S.V.); candeias@uevora.pt (A.C.)

2 City University of Macau Chair in Sustainable Heritage, University of Evora, 7000-671 Evora, Portugal

3 Consortium HERITAS-Estudos de Património, University of Evora, 7000-645 Evora, Portugal; silvia.scardina@campus.ul.pt

4 Museu Nacional Frei Manuel do Cenáculo (Evora), 7000-804 Evora, Portugal; francisco.bilou@gmail.com

* Correspondence: cpm@uevora.pt

\begin{abstract}
In recent decades, many works have been devoted to the study of materials and painting techniques used to produce illuminated manuscripts. If the analyses were once largely invasive, the approach has become increasingly more in situ and non-invasive over the years. This work presents the results of the analysis of the Portuguese Charter of Évora, an illuminated manuscript that dates back to 1501, combining an elemental mapping technique (MA-XRF) with the non-invasive imaging techniques of infrared reflectography and digital microscopy. Remarkably, this approach allowed us to obtain unexpected results regarding the chronology of production of the illumination of the view of the City of Évora and of the Charter of Évora itself, posing new questions for art history on the political, social and artistic context of the early 16th century City of Évora.
\end{abstract}

Keywords: infrared reflectography; MA-XRF; digital microscopy; illuminations; underlayers assessment

\section{Introduction}

Illuminated manuscripts are among the best testimonies of art, culture, politics and religion between the Mediaeval and Renaissance periods. A good example is the Portuguese Manueline Charters. These charters were produced in the framework of a deep reform of the Charters of the Portuguese cities and villages carried out by the King D. Manuel I (1469-1521) as a response of the king who, for decades, had demanded an update of the texts relating to administrative procedures, the economy, taxes, the inhabitants' relationship with the central power and with the landlords. Within this reform, about 580-600 charters were produced, among which is the Charter of Évora [1,2]. Despite the authorship of the texts being the responsibility of the authorities of the Kingdom, it was up to the local authorities to financially support the production of the Charters and their illuminations. In this sense, to study the materials and painting techniques of these illuminated Charters is to highlight the cultural, political and financial capability of each Portuguese village and city at the time of their production.

Dating back to 1 September 1501, the Charter of Évora was the second Charter to be signed by D. Manuel I, just one year after the signing of the Charter of Lisbon, which was the capital of the Kingdom at the time. Its authorship is not consensual among historians, floating between Duarte de Armas and Garcia de Resende. From the set of known Charters that have reached us, the Charter of Évora is the only one that features a representation of the view of the city at the time of its production [3]. The Charter represents 
a unique record of the city's urban organisation, allowing for the identification of ongoing construction contracts and of missing buildings over time (Figure 1, left). Furthermore, the representation of the city according to the perspective adopted by the author of the charter led to reconfigure many buildings, making the representation more idealised than real, following a practice still stuck to the conventions of the medieval world.

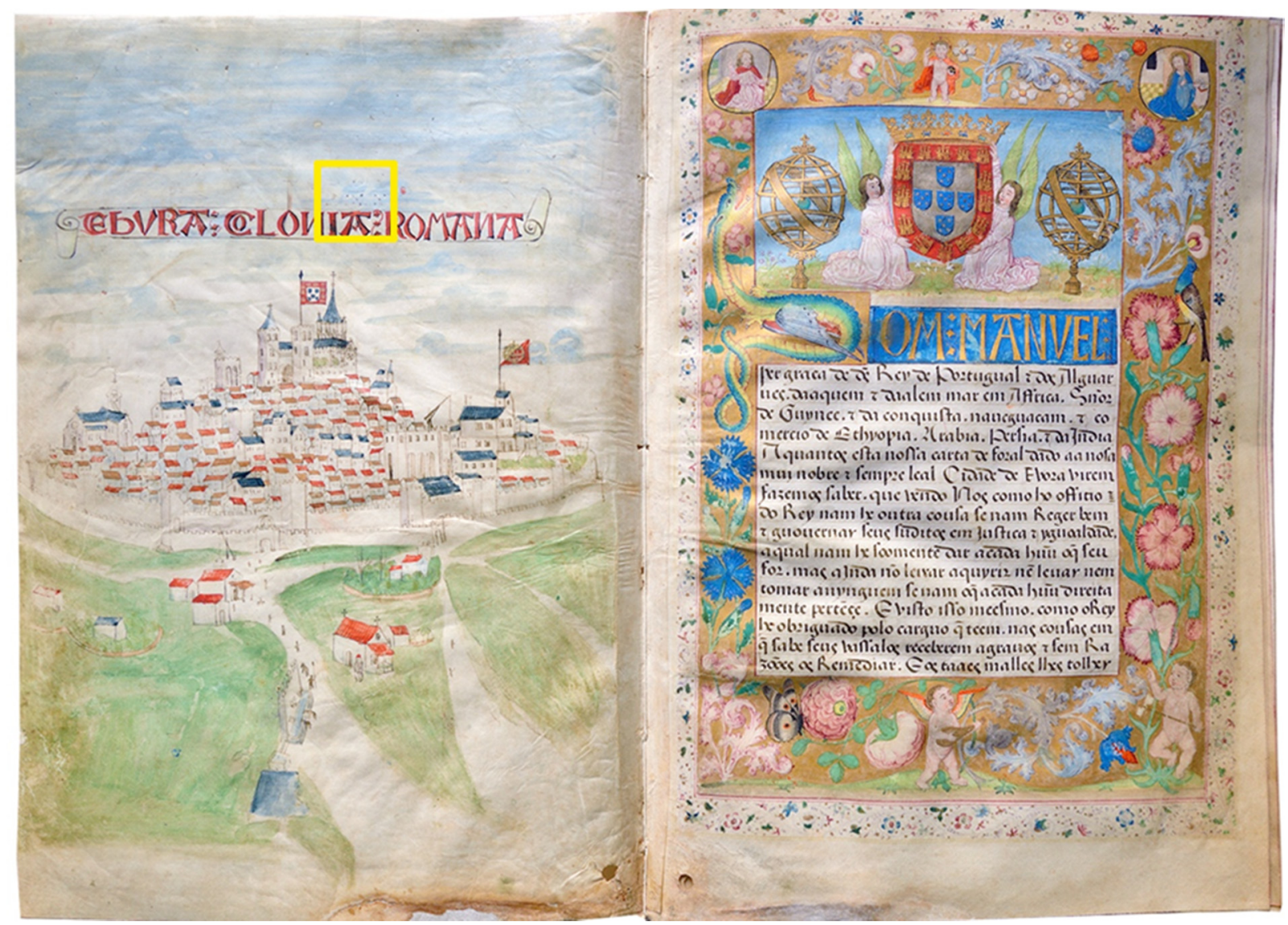

Figure 1. Full-size images of the two illuminated folia (left, f.1v; right, f.2) present in the Charter of Évora $(290 \mathrm{~mm} \times 208 \mathrm{~mm}$ ). Highlighted in yellow, one of the studied regions of interest, where a trace of an image appears to be present under the caption over the city. Photo @ C HERCULES Lab.

In recent decades, many works have been devoted to the study of the materials and painting techniques used to produce illuminated manuscripts [4-6]. In the Portuguese context, the Manueline Charters have been subjected to several studies, not only because of their historical and artistic importance, but because they are important fingerprints of the early 16th century Portuguese workshops for producing illuminated manuscripts [3,7-10]. In 2017, a study including the characterisation of the materials employed to produce the illuminations of the Charter of Évora reflected the use of high-quality materials: yellows were produced with lead tin yellow (type I), blues with azurite or indigo, greens with malachite or by mixing lead tin yellow with azurite, reds with vermilion, pinks with a lake pigment, blacks with carbon black and silver and gold with high-pure metal alloys (Ag:Cu, 99.7:0.3, \%wt; $\mathrm{Au}: \mathrm{Cu}, 99: 1, \% w t)$. The paints were often produced by mixing the pigment with chalk as an extender, in a polysaccharide medium [3]. Despite the identification of such rich and high-quality colour-palette, much about this illuminated Charter was yet to be unveiled.

This work focuses on the study of three specific areas of the illumination: the view of the City of Évora (Figure 1, left), the caption over the city and what appears to be a trace of an image present under the caption over the city (Figure 1, left, yellow highlight). As it is 
something not explicitly observable with the naked eye, this issue has not been studied to date. Nevertheless, the investigation of these areas combining an elemental mapping and non-invasive imaging techniques revealed the original idea of the artist in his first approach to this illumination, and at the same time, it highlighted the intervention procedure that might have followed to mask this first attempt of the artist. For this purpose, in situ and non-invasive analysis were performed, namely infrared (IR) reflectography, macro X-ray fluorescence (MA-XRF) and digital microscopy (DM).

IR reflectography was used to infer on the presence of underdrawings or any missed details that could provide any information regarding how the representation that was once present in this region could have looked. This technique has been widely used for underdrawings analysis in paintings, namely on canvas and wood paintings [11,12]. Recently, the technique was applied to the study of the underprintings in illuminated incunabula, providing interesting results on the historical-artistic information present under the paint layers [13]. MA-XRF was performed as a complement to IR reflectography to evaluate the homogeneity of the elemental composition of the paints laying beneath this region. MA-XRF was used in the last few years for two-dimensional elemental characterisation of paint layers, to obtain elemental mapping of the materials present in paints or the use of metal point preparatory drawings in illuminated manuscripts [14-18]. Finally, DM was carried out to evaluate the stratigraphic application of the paint layers. This is one of the most powerful techniques for a fast microscopic analysis of paint surfaces. Nowadays, with the development of ultra-high resolution of motorised lenses, high precision 3D reconstructions at high magnifications might be reached with reduced distortion, allowing an in situ, fast and accurate analysis of the surface's morphology and layers' overlayers [19].

The multi-analytical protocol followed in this work allowed for the achievement of interesting results able to provide new information about art history that will greatly contribute to an advance in the state of the art with regard to the history of the City of Évora in its political, social and artistic context.

\section{Methods}

The study started with a detailed observation of the illuminations under a stereomicroscope. The aim was to evaluate the presence of underdrawings in the selected region with the title of the City of Évora. IR reflectography was performed over the same entire folium. Visible and IR reflectography images were compared. Finally, to infer the consistency of the materials used to produce the caption of the illumination, MA-XRF and 3D digital microscopy analyses were performed in a selected region of interest considering the differences observed from the IR reflectography results.

\subsection{Digital and Stereomicroscopy}

To infer the occurrence of furrows related to an underdrawing beneath the City of Evora's illumination, magnified images were acquired under a LEICA M205C stereomicroscope with a zoom range of $7.8 \times$ to $160 \times$ equipped with a Leica DFC295 camera and an external racking illumination by optical fibres.

Both painting technique and chronological application of paint layers were analysed using 3D magnified images acquired with an HRX-01 HIROX Digital Microscope equipped with a $5 \mathrm{MP}$ sensor to suit $4 \mathrm{~K}$ resolution and motorised HR lenses. The HR-5000E lens at $0^{\circ}$ of inclination related to the normal were used to observe the object at $140 \times$ magnifications under the mere top lighting system (96\% intensity). At this magnification, 2-D highresolution, fully focused still images $(1530 \times 2040$ pixel, $\mathrm{H} \times \mathrm{L})$ of multiple focal planes were compiled by acquiring individual images of the analysis spots at several heights, which were later merged with the automated function of the XRX-01 software. In addition, 3D profiles of the spots were constructed similarly, retaining the information of the height to generate pseudo-colour maps and a related side bar with the topography range (expressed in relative $\mu \mathrm{m}$ ). Calibration for the level of white was left in standard mode. 
As for the underlayers assessment, a high-resolution IR reflectography camera OSIRIS equipped with an InGaAs detector sensitive in the 900-1700 nm spectral range was used. To ensure that the total light reaching the detector was only concerned with infrared radiation, the system setting was equipped with a long pass filter Schott RG850 to block the wavelength below $850 \mathrm{~nm}$. Normal lenses were used, with a working distance to the object of $60 \mathrm{~cm}$, a reding scale of 60 and an objective aperture of $\mathrm{f} / 8$. A slow scan of 10 minutes per area and an integration time of $10 \mathrm{~m} / \mathrm{s}$ was carried out. The diffuse illumination system was composed of two 1000 W Tungsten Halogen VC-1000 Q Quartz light system (3200 K colour temperature). To ensure a homogeneous illumination all over the surface of $50 \mathrm{~Hz}$, a luximeter was used. To reduce undesired reflexions of light, the lamps were empirically disposed to create an angle of incidence at around $50^{\circ}$. The distance between the lamps and the object was set to provide the best covering illumination and the lowest surface temperature increase. The surface temperature of the object was consistently controlled by using an in situ laser temperature reading (surface temperature was never overpassing more than $5 \%$ of room temperature

Two acquisitions were recorded: one considering the area of the red caption "EBVRA COLONIA ROMANA", with a final resolution of $1024 \times 4096$ pixel, $\mathrm{H} \times \mathrm{L}(2 \times 4$ mosaic tiles8 tiles in total) and a second one regarding whole page, final resolution $4096 \times 4096$ pixel, $\mathrm{H} \times \mathrm{L}(4 \times 4$ mosaic tiles -16 total $)$.

\subsection{Elemental Characterisation}

For the study of the painting techniques, an ELIO MA-EDXRF scanning spectrometer (BRUKER), equipped with a $17 \mathrm{~mm}^{2}$ XGLab srl, was used. An ultra-fast Silicon Drift Detector (also knowns as CUBE technology), an X-ray tube Rh (ex-citation source), $1 \mathrm{~mm}$ collimation, and an integrated video microscope camera for magnified image of the analysis area were employed. An external USB HD video camera for large field of view images, axial and focal laser for precise analysis point adjustment was used. In this ELIO MA-EDXRF system, the angle ( $90^{\circ}$ perpendicular to the surface) and working distance ( $2 \mathrm{~mm}$ to the surface) were fixed and defined. The geometry parameters are carefully controlled by support of two lasers (axial and focal with independent software control), allowing an easy alignment and analysis point identification. A motorised XY stage, mounted on a tripod for 2D mapping with a maximum total travel of around $15 \mathrm{~mm} \times 15 \mathrm{~mm}$ was used. The automatic control and map visualisation was provided by the use of full integrated mapping software from BRUKER. Following the optimised experimental conditions by the team in previous works [13], analyses were carried out at $40 \mathrm{kV}$ and $30 \mu \mathrm{A}$, without filter, a pixel time of $3 \mathrm{~s}$, a map step of $500 \mu \mathrm{m} \times 500 \mu \mathrm{m}$ (70 rows $\times 70$ columns) with an area of analysis of $3.5 \mathrm{~cm} \times 3.5 \mathrm{~cm}$ and $4 \mathrm{~h}$ mapping acquisition.

\section{Results}

Throughout the Middle Ages and the Renaissance period, the language of heraldic assumed an important role for nobility. In fact, every detail present in a coat of arms reflected the history of the noble who carried it, ranking him and his family among the noble class and high among the society of the time. As a consequence, strict rules were followed in its design and in its reproduction.

In the Charter of Évora, three different coats of arms are present: two appear in the representation of the City of Évora (fol. 1v) and another one on its frontispiece (fol. 2) (Figure 1). With a similar size, the two flags exhibited in the representation of the City of Évora stand out for the difference of the drawing technique (Figure 2a,b): the flag hoisted on the Cathedral of Évora, with the arms of the Kingdom, reflects a less skilled and detailed drawing when compared with the flag with the personal arms of King D. Manuel I (Figure 2c). This latter is hoisted on the palace that the king occupied during his stays in Evora, drawn with a more detailed and refined technique. 

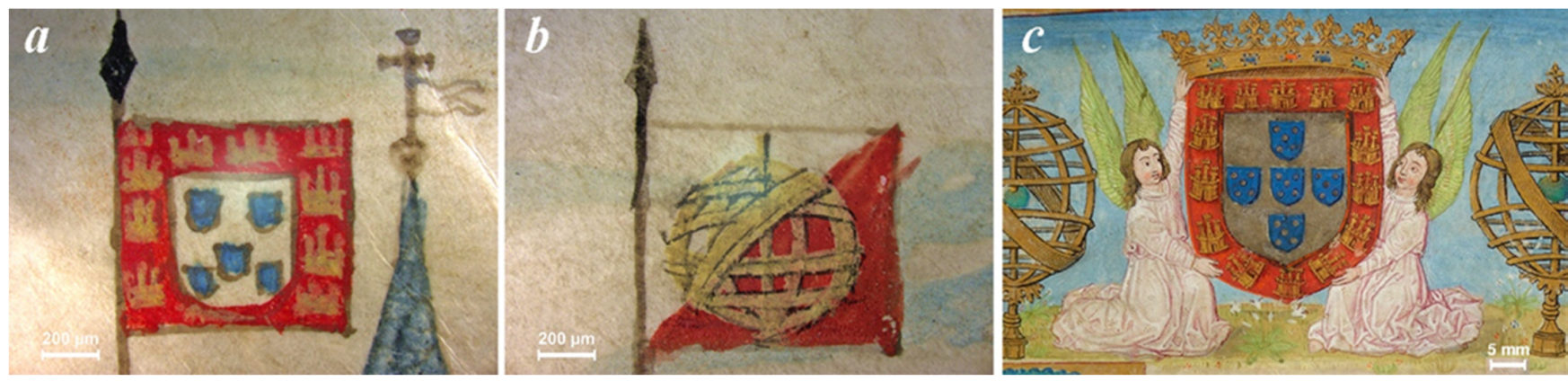

Figure 2. Magnified images of the flags and coat of arms present in the Charter of Évora: (a) flag hoisted on the Cathedral of Évora (f.1v); (b) flag hoisted on the Palace of King D. Manuel I (f.1v); and (c) coat of arms of the Kingdom of Portugal (f.2).

Following a visual comparison between the coat of arms of the Kingdom represented on the flag hoisted above the Cathedral (Figure 2a) and the one on the frontispiece of the Charter of Évora (Figure 2c), important differences emerge, mainly in the disposal of the five blue shields (for heraldry, a shield-or escutcheon-is the main element of an achievement of arms, upon which a coat of arms is depicted). The heraldic insignia of the frontispiece (Figure 2c) adopts the model of the period, i.e., a Cross of Christ made of five blue shields, each one charged with five silver bezants (a heraldic charge introduced in the coat of arms of many returned western European knights during the crusading era), forming a cross of Saint Andrew [20]. This heraldic was in use since the King Afonso I of Portugal (1139-1185) [21], but the azure cross of the Cathedral's flag forms an x-shaped Saint Andrew's cross by itself, not through plates lodged within escutcheons. This composition contradicts the heraldic language traditionally followed at that time about the arms of the Kingdom of Portugal (Figure 2). As such, some questions have arisen. How was it possible that an illuminator, who followed such a realism in the representation of the city, was not aware of what concerned the matters of the Kingdom? Can the royal flag reveal an old representation once used regionally? A first observation to be made is that the illuminator who drew the City of Évora may not have been the same person who drew the frontispiece of the Charter. Furthermore, it is also very likely that the author of the flag hoisted on the Cathedral of Évora had a very limited knowledge of the Portuguese heraldic language of this period. In the following pages, these questions will be addressed through a multi-analytical approach.

\subsection{Stereomicroscopy}

The observation under a stereomicroscope using visible racking light suggests the presence of furrows likely related to the dry point marking of five shields displaced forming a Cross of Christ, formerly present in this region (Figure 3a). If they have existed, these shields would have been correctly arranged according to the heraldic language in use at the time, i.e., cross, with the florins arranged to form a Cross of Saint Andrew (Figure 3b). This becomes clear according to the reconstruction manually performed based on the traces identified with ranking light in this region (Figure 3b).

To evaluate the existence of traces of underdrawings and/or underpaintings that could corroborate the pre-existence of a coat of arms in this place, infrared reflectography and MA-XRF were used to trace the presence of carbon-based charcoal and any other chemical element, respectively. 


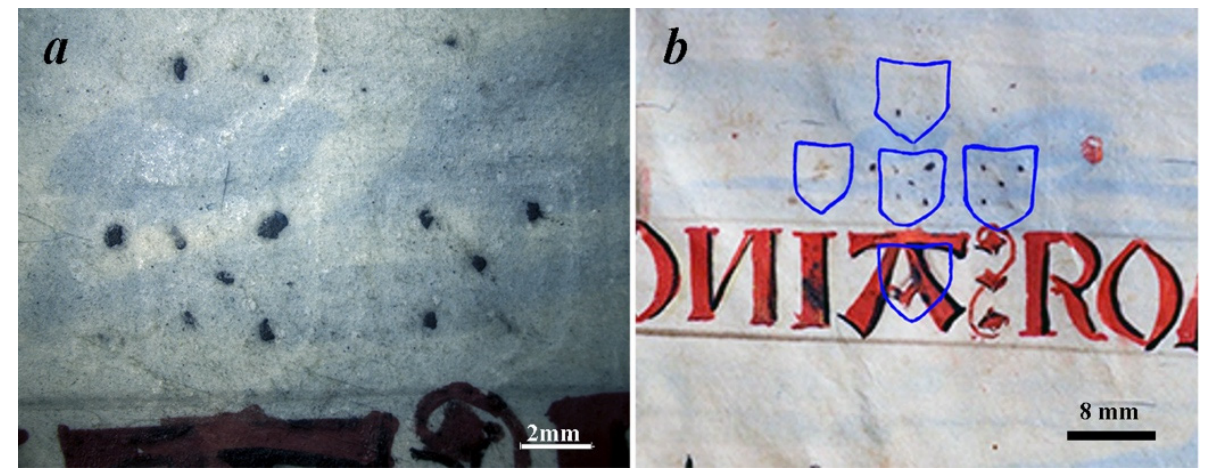

Figure 3. Observation under a stereomicroscope of the City of Évora: (a) signs the furrows of undercoat of arms in the City of Évora observed under racking light; (b) in blue, manual reconstruction of the furrows.

\subsection{IR Reflectography}

The analysis of the whole folium with the view of the City of Évora by IR reflectography brought to light interesting features, that can be summarised as (1) no IR reflective-based underdrawings (such as carbon-based underdrawings) were identified for the architectural representations; (2) only the flag with the arms of King D. Manuel I has a final blackoutline produced with an IR reflective-based paint; (3) no signs of IR reflective-based underdrawings appear in the area where once a previous drawing might have been present; and (4) the caption "EBVRA COLONIA ROMANA" shows a different response to the infrared radiation.

In more detail, from a historic and art history perspective, the fact that no infrared reflective-based preparatory drawings (such as the carbon-based materials often used for underdrawings in paintings) were identified for the representation of the City of Évora suggests it has been drawn straight to the parchment by the illuminator. This situation reflects the good skill and ability of the illuminator in drawing these themes (Figure $4 b$ ).

Furthermore, the fact that the armillary sphere in the arms of the King D. Manuel I has a final black-outline produced with an IR reflective material also imply that it might have received special attention, either by the illuminator as a final retouch, or by anyone who might have retouched part of the caption with an IR reflective material (Figure 4b).

Regarding the area of the representation likely shown originally in the region of the caption (Figure 3), no signs of underdrawings are currently visible by IR reflectography. This suggests that what is now visible/observable by digital microscopy under racking light, might likely be the marking of a drawing made with a groove, which could have been made either with a metallic tip or with any other non-metallic object.

Finally, the difference of response to IR radiation of the caption "EBVRA COLONIA ROMANA" (Figure 5) revealed a transitory region placed in the same place of the representation meanwhile disappeared. This further revelation is quite surprising since it allows to suppose that (a) the retouching with an IR reflective-based material of the letters placed on the region where once another representation might have been present is a reasonable hypothesis; (b) the non-retouched extended to the entire caption is an argument hard to explain. 


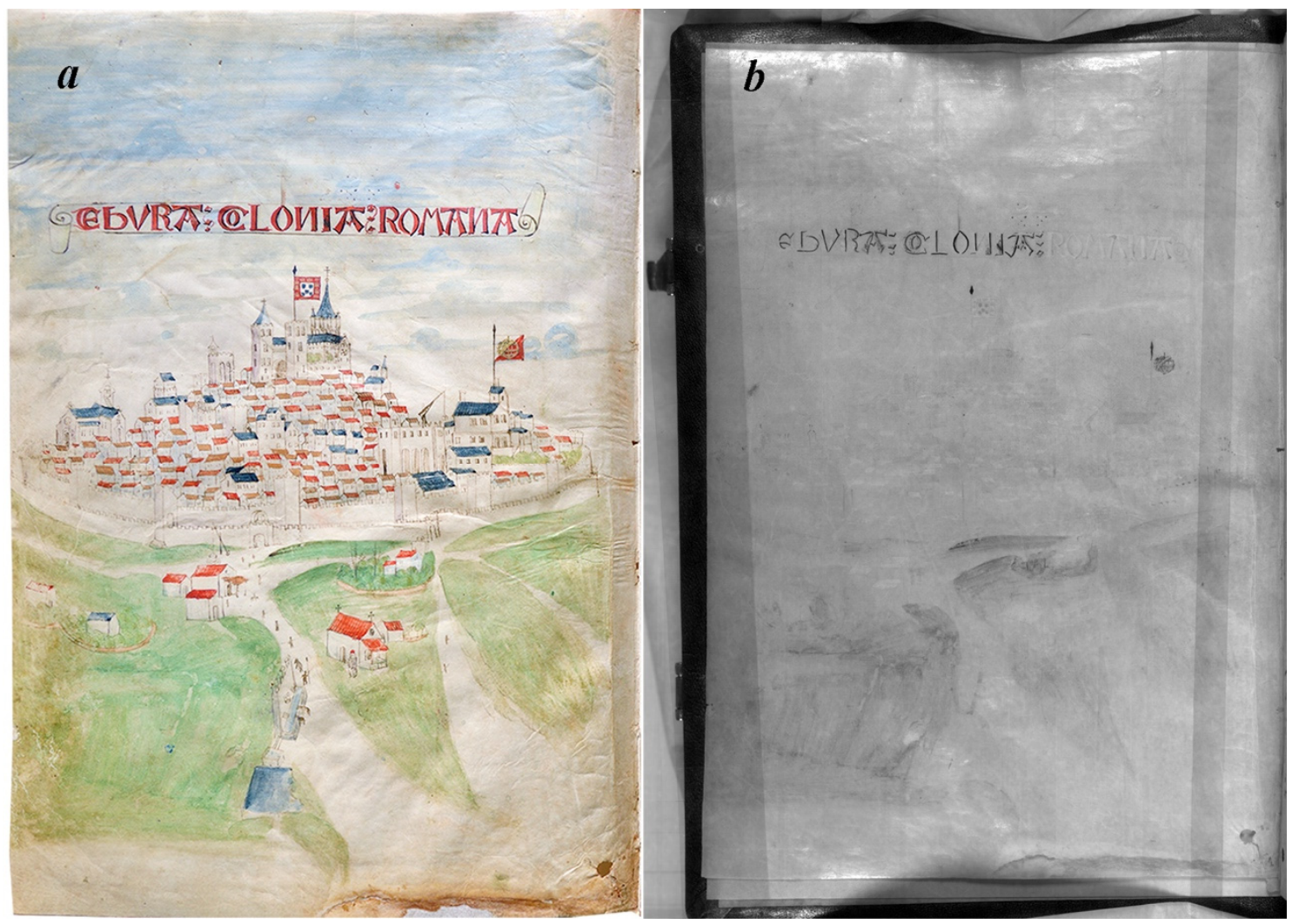

Figure 4. Full-size images of the folium presenting the view of the City of Évora in the Charter of Évora: (a) visible image; (b) infrared reflectography image.
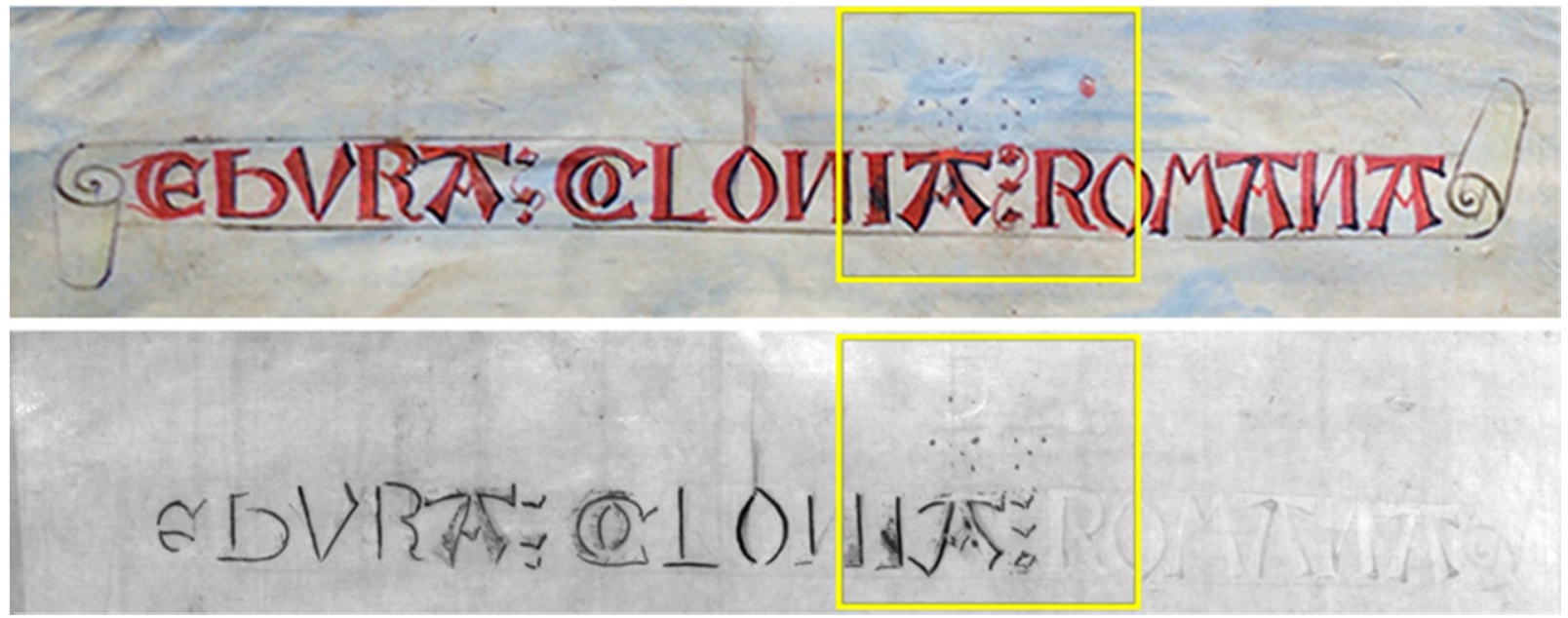

Figure 5. Magnified images of the folium presenting the view of the City of Évora in the Charter of Évora. Up, visible image; down, infrared reflectography image. Highlighted in yellow is the region of interest selected for analysis by MA-XRF.

\subsection{MA-XRF and Digital Microscopy}

MA-EDXRF on the handwritten "EBVRA COLONIA ROMANA" reveals that mercury $(\mathrm{Hg})$ was used to produce the red letters of the caption of "COLONIA", and a mixture of mercury $(\mathrm{Hg})$ and iron $(\mathrm{Fe})$, probably a mixture of vermilion $(\mathrm{HgS})$ with an ochre, was employed to produce the world "ROMANA" (Figure 6a,b). The red paint composition change is placed in the " $\mathrm{A}$ " of "COLONIA". In fact, according to Figure 6a,b, the left branch of the " $\mathrm{A}$ " has a higher $\mathrm{Hg}$ concentration when compared to the right "branch" that reveals 
a mixture of an ochre with vermilion. Additionally, the ratio of the relative intensities of the L-alpha line to L-beta line of mercury varies from around 1.98 in the left "branch" to 1.25 in the right "branch" indicating that there is an increase in thickness in the right side with attenuation of the L-alpha sign from the deeper layers. This finding is corroborated by $3 \mathrm{D}$ digital microscopy analysis that showed that the ink layer of this right "branch" is about $35 \mu \mathrm{m}$ thicker when compared to the ink layer of the left "branch" of the letter " $\mathrm{A}$ ", suggesting that it could result from a layer added over a pre-existing layer (Figure 7).
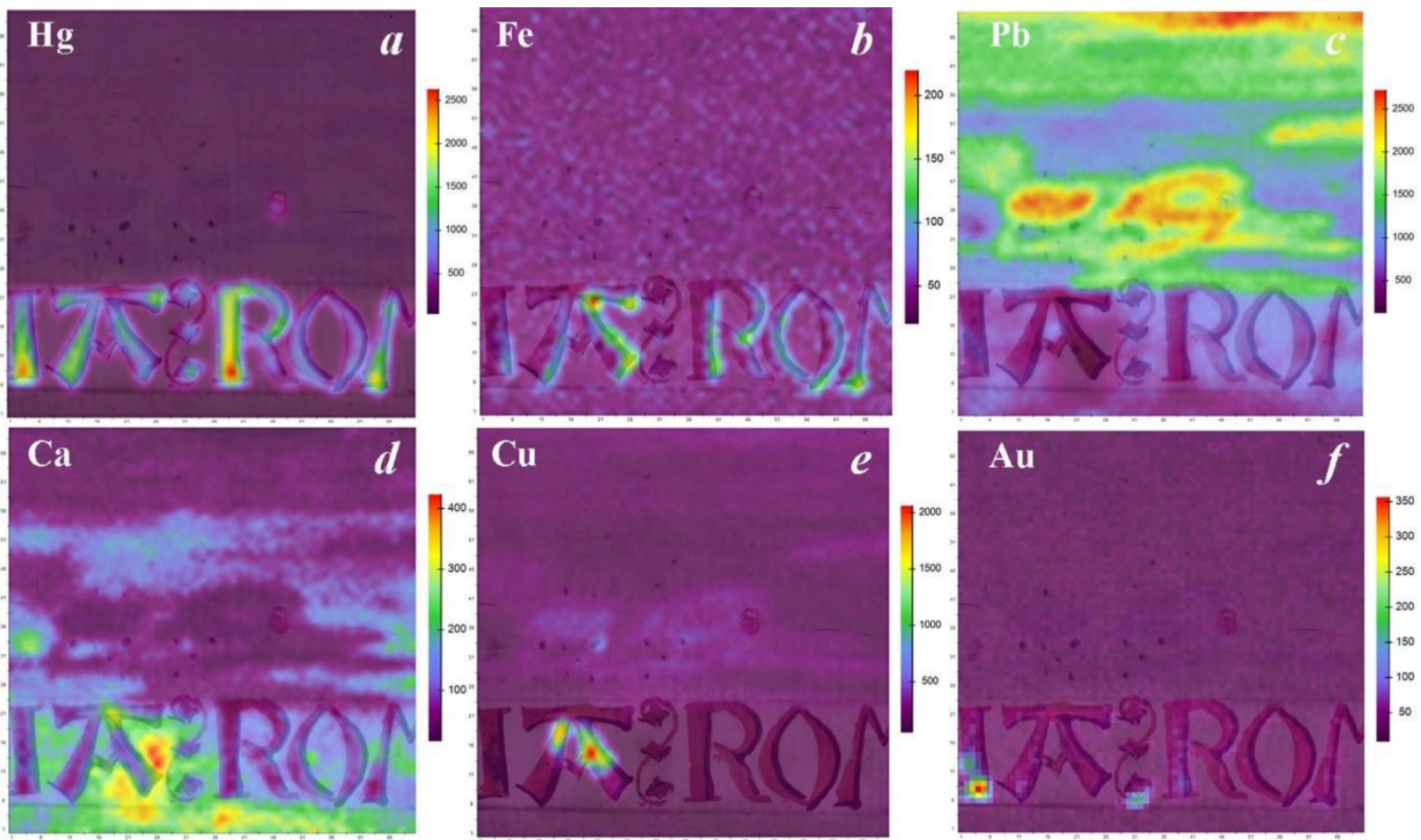

Figure 6. ELIO MA-EDXRF (a) mercury (Hg), (b) iron (Fe), (c) lead (Pb), (d) calcium (Ca), (e) copper $(\mathrm{Cu})$ and $(\mathbf{f})$ gold $(\mathrm{Au})$ elemental analysis of a selected region in the caption present in the view of the City of Évora.
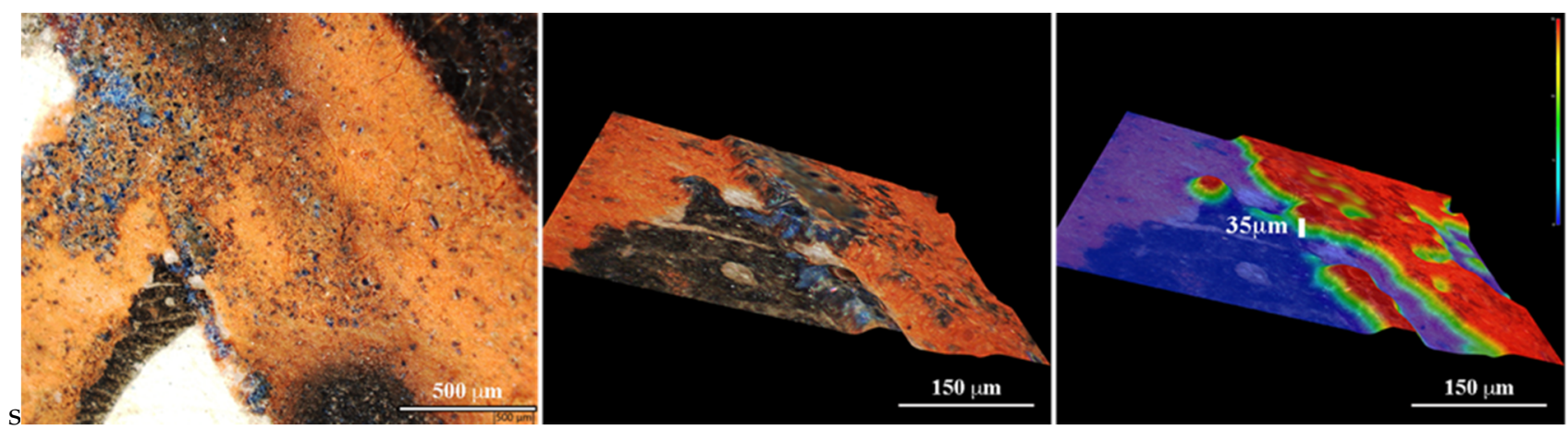

Figure 7. Details of the "A" letter of "COLONIA". From left to right: digital image, 3D-image and false-colour topographic image.

A mixture of lead $(\mathrm{Pb})$ and copper $(\mathrm{Cu})$ was used to produce the blue-sky paint (Figure $6 c, e)$. These results are in agreement with those found in a previous analytical study of the Charter of Évora, where micro-FTIR analysis allowed to identify the use of lead white $\left(2 \mathrm{PbCO}_{3} \cdot \mathrm{Pb}(\mathrm{OH})_{2}\right)$ and of azurite $\left(2 \mathrm{CuCO}_{3} \cdot \mathrm{Cu}(\mathrm{OH})_{2}\right)$ to produce the blue-sky paint [3]. Lead $(\mathrm{Pb})$ was also identified in high concentration in the light-blue clouds 
(Figure 6c). Calcium (Ca) was detected in the white clouds, and, in highest concentrations, at the bottom of the text, a fact that might be related to a paint re-integration of the region where once a previous drawing was present (Figure 6d). These results are in agreement with those found in the already mentioned study of the Charter of Évora [3], where microFTIR analysis identified the presence of calcium carbonate $\left(\mathrm{CaCO}_{3}\right)$ in these regions. The high concentration of copper $(\mathrm{Cu})$ in the " $\mathrm{A}$ " of "COLONIA" is a reflection of a higher concentration of the blue pigment azurite in this region (also visible under the HIROX digital microscope, Figure 7), which must have been deposited in greater concentration in this area to better disguise the presence of traces of the formerly existing paint layer.

Regarding the five bezants which were placed forming a cross of Saint Andrew inserted in the remains of the three shields (see Figure 5), the analysis by infrared reflectography combined with MA-XRF suggests that they might all have been drawn with an IR-reflective material, such as a carbon-based ink. Under a digital microscope, it is possible to verify that these bezants are displayed over the blue-sky paint (Figure 8). This suggests that it shall not be part of the original underlayer but might correspond to a later addition, that could well have occurred contemporarily with the "ROMANA" word.
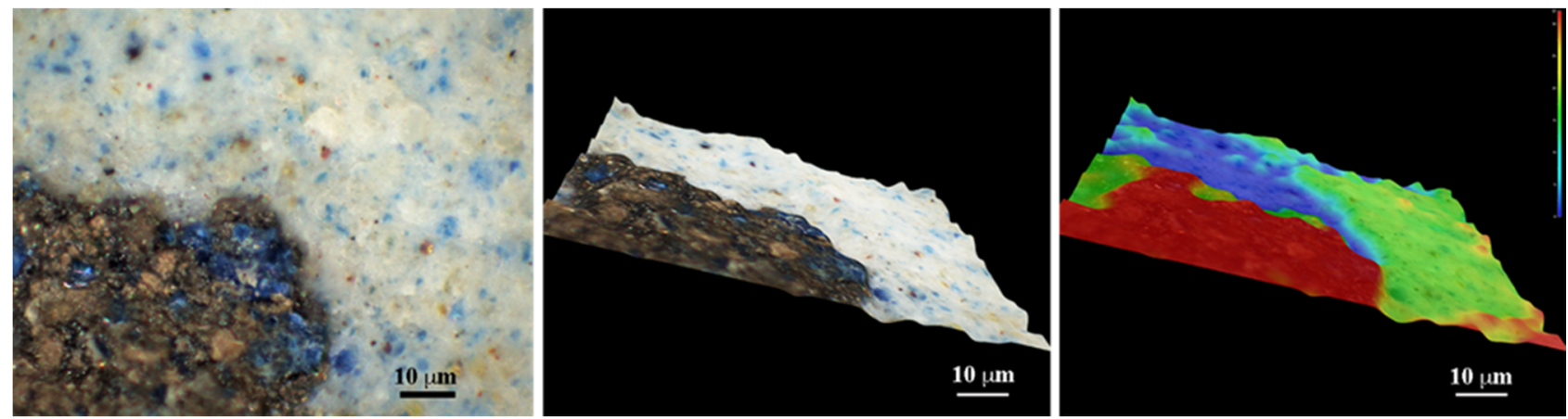

Figure 8. Details of a bezant placed over the blue-sky paint layer. From left to right: digital image, 3D-image and false-colour topographic image.

Finally, MA-XRF mapped the occurrence of gold remains in some aeras of the IRreflective part of the caption (Figures 5 and $6 \mathrm{f}$ ). Digital microscopy analysis allowed to observe that these gold traces are mixed with the black ink and correspond to a top layer of the paint composition (Figure 9). Moreover, its morphologic appearance suggests the use of gold as a pigment, in agreement with what was found for producing the gold paints in the frontispiece of the Charter of Évora (Figure 1, right) [3].
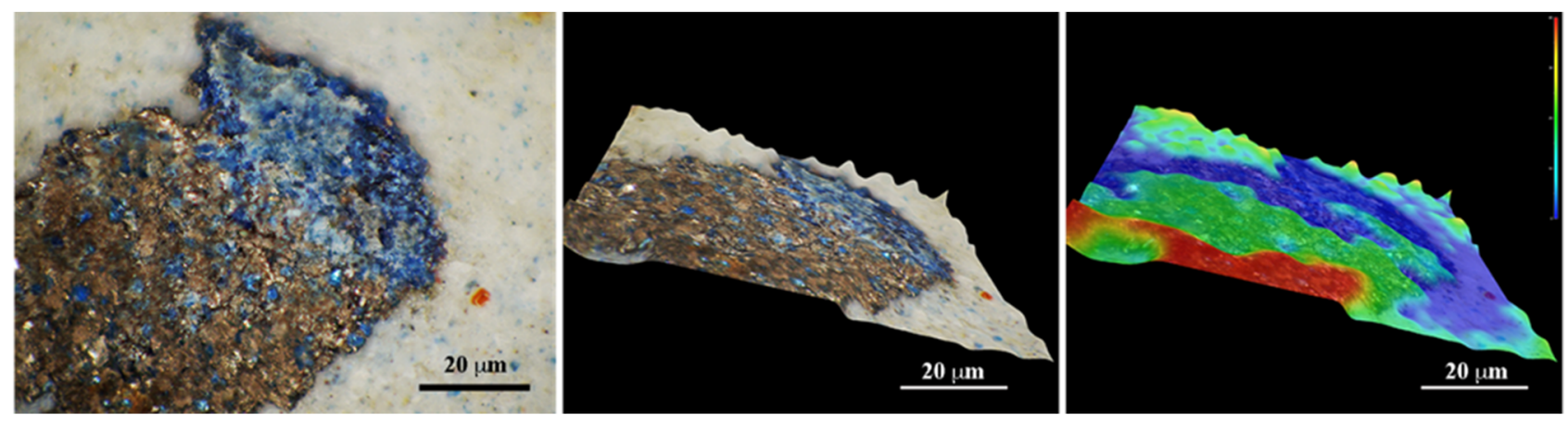

Figure 9. Details of a bezant placed over the blue-sky paint layer. From left to right: digital image, 3D-image and false-colour topographic image. 


\section{Conclusions}

The multi-analytical protocol followed in this work opened an important door on what may be the yet unknown message about the historical production of the Charter of Évora, shedding new insight on the city's past. The DM and racking-light stereomicroscopy results allowed us to a) identify the pre-existence of a coat of arms (or of a standard) with the arms of the Kingdom of Portugal in the centre of the page; and b) infer its removal from iconographic composition of the City of Évora, suggesting a change in the iconographical message of this Charter. IR reflectography revealed the good skills of the illuminator to draw the city view. In this respect, data suggest that he was not an amateur and it is therefore unlikely that he made a mistake drawing the city plan. At the same time, MA-XRF led to the identification of (a) a change in the red-writing paint's composition of the title; and (b) the procedures followed to cover up the first layout approach.

Within these results, a new narrative is possible: from the early 16th century onwards, Évora is no more considered an important city of the Portuguese kingdom but it is regarded as a clone of Rome-the capital of the Roman Empire. Considering that the illuminations of the Manueline Charters were generally financed by local authorities, analytical data provided by this paper could reveal a slightly different narrative, in which at some point, local power aimed to flaunt Évora's superior political status, shows the city much closer to the Roman Empire and to its glorious past than to other contemporary Portuguese cities.

Author Contributions: Conceptualisation, C.M. and F.B.; methodology, C.M.; formal analysis, C.M., C.B., S.V., A.C. and S.B.-S.; investigation, F.B.; writing-original draft preparation, C.M.; writingreview and editing, C.B., S.V. and S.B.-S. All authors have read and agreed to the published version of the manuscript.

Funding: This work was supported by Portuguese national funds through the FCT—Fundação para a Ciência e a Tecnologia, I.P., within the projects UIDB/04449/2020 and UIDP/04449/2020 (HERCULES Laboratory). C.M. thanks, DL57/2016/CP1372/CT0012 ("Norma Transitória") and S.B.S. thanks the HERITAS program PD/297/2017. C.M., C.B., S.V., and A.C. also acknowledge the City University of Macau Chair in Sustainable Heritage.

Data Availability Statement: In this section, please provide details regarding where data supporting reported results can be found, including links to publicly archived datasets analysed or generated during the study. Please refer to suggested Data Availability Statements in section "MDPI Research Data Policies" at https:/ / www.mdpi.com/ ethics (accessed on 20 January 2022). You might choose to exclude this statement if the study did not report any data.

Acknowledgments: The authors gratefully acknowledge Fabio Sitzia (HERCULES Lab, University of Évora, Portugal) for supporting the 3D digital images acquisitions, and to the Câmara Municipal de Évora (Portugal) for access to the study of the Charter of Évora.

Conflicts of Interest: The authors declare no conflict of interest.

\section{References}

1. Garcia, J.M. Os Forais Novos do Reinado de D. Manue I.; Colecção do Banco de Portugal: Lisboa, Portugal, 2009.

2. Branco, M.J.; Bilou, F. (Eds.) Forais Manuelinos. Juromenha-Alandroal-Terena (1512-1516); Edições Colibri: Lisbon, Portugal, 2016.

3. Miguel, C.; Barrocas Dias, C.; Ferreira, F.; Candeias, A. The comparative study of four Portuguese sixteen century illuminated Manualine Charters based on spectroscopy and chemometrics analysis. Appl. Phys. A 2017, 123, 72. [CrossRef]

4. Panayotova, S.; Ricciardi, P. (Eds.) Manuscripts in the Making: Art and Science; Harvey Miller/Brepols: London, UK; Turnhout, Belgium, 2018; Volume 2.

5. Melo, M.J.; Nabais, P.; Araújo, R.; Vitorino, T. The conservation of medieval manuscript illuminations: A chemical perspective. Phys. Sci. Rev. 2019, 4, 20180017. [CrossRef]

6. Vetter, W.; Latini, I.; Schreiner, M. Azurite in medieval illuminated manuscripts: A reflection-FTIR study concerning the characterization of binding media. Herit. Sci. 2019, 7, 21. [CrossRef] [PubMed]

7. Moura, L.; Melo, M.J.; Casanova, C.; Claro, A. A study on Portuguese manuscript illumination: The Charter of Vila Flor (Flower town), 1512. J. Cult. Herit. 2007, 8, 299-306. [CrossRef]

8. Manso, M.; Le Gac, A.; Longelin, S.; Pessanha, S.; Frade, J.C.; Guerra, M.; Candeias, A.; Carvalho, M.L. Spectroscopic characterization of a masterpiece: The Manueline foral charter of Sintra. Spectrochim. Acta Part A 2013, 105, 288-296. [CrossRef] [PubMed] 
9. Le Gac, A.; Nogueira, I.D.; Guerra, M.; Frade, J.C.; Longelin, S.; Manso, M.; Pessanha, S.; Seruya, A.I.M.; Carvalho, M.L. Microscopy and X-Ray Spectroscopy Analyses for Assessment of Gilding and Silvering Techniques of Portuguese Illuminated Manuscripts. Microsc. Microanal. 2015, 21, 20-55. [CrossRef] [PubMed]

10. Guerra, M.; Carvalho, M.L.; Le Gac, A.; Manso, M.; Mortari, C.; Longelin, S.; Pessanha, S. New insights into the red and green pigments in the illuminated foral charter of Setubal (1515) by combined use of $\mu$-Raman and X-ray fluorescence spectrometry. $J$. Appl. Phys. 2016, 119, 10. [CrossRef]

11. Mercuri, F.; Buonora, P.; Cicero, C.; Helas, P.; Manzari, F.; Marinelli, M.; Paoloni, S.; Pasualucci, A.; Pinzari, F.; Romani, M.; et al. Metastructure of illuminations by infrared thermography. J. Cult. Herit. 2018, 31, 53-62. [CrossRef]

12. Antunes, V.; Candeias, A.; Mirão, J.; Carvalho, M.L.; Barrocas Dias, C.; Manhita, A.; Cardoso, A.; Francisco, M.J.; Lauw, A.; Manso, M. Analytical characterization of the palette and painting techniques of Jorge Afonso, the great 16th century Master of Lisbon painting workshop. Spectrochim. Acta A Mol. Biomol. Spectrosc. 2018, 193, 264-275. [CrossRef]

13. Miguel, C.; Bottura, S.; Ferreira, T.; Fialho Conde, A.; Barrocas-Dias, C.; Candeias, A. Unveiling the underprintings of a latefifteenth-early-sixteenth century illuminated French incunabulum by infrared reflectography. J. Cult. Herit. 2019, 40, 34-42. [CrossRef]

14. Bicchieri, M.; Biocca, P.; Caliri, C.; Romano, F.P. Complementary MA-XRF and $\mu$-Raman results on two Leonardo da Vinci drawings. X-ray Spectrom. 2021, 50, 401-409. [CrossRef]

15. Mazzinighi, A.; Ruberto, C.; Castelli, L.; Czelusniak, C.; Giuntini, L.; Mandò, P.A.; Taccetti, F. MA-XRF for the Characterisation of the Painting Materials and Technique of the Entombment of Christ by Rogier van der Weyden. Appl. Sci. 2021, 11, 6151. [CrossRef]

16. Magkanas, G.; Bagán, H.; Sistach, M.C.; García, J.F. Illuminated manuscript analysis methodology using MA-XRF and NMF: Application on the Liber Feudorum Maior. Microchem. J. 2021, 165, 106112. [CrossRef]

17. Sottili, L.; Guidorzi, L.; Mazzinighi, A.; Ruberto, C.; Castelli, L.; Czelusniak, C.; Giuntini, L.; Massi, M.; Taccetti, F.; Nervo, M.; et al. The Importance of Being Versatile: INFN-CHNet MA-XRF Scanner on Furniture at the CCR "La Venaria Reale". Appl. Sci. 2021, 11, 1197. [CrossRef]

18. Watteeuw, L.; Van Bos, M.; Gersten, T.; Vandermeulen, B.; Hameeuw, H. An applied complementary use of macro X-ray fluorescence scanning and multi-light reflectance imaging to study Medieval Illuminated Manuscripts. The Rijmbijbel of Jacob van Maerlant. Microchem. J. 2020, 155, 104582. [CrossRef]

19. Elkhuizen, W.S.; Callewaert, T.W.J.; Leonhardt, E.; Vandivere, A.; Song, Y.; Sylvia, C.; Pont, J.M.P.; Joris, D. Comparison of three 3D scanning techniques for paintings, as applied to Vermeer's 'Girl with a Pearl Earring. Herit. Sci. 2019, 7, 89. [CrossRef]

20. Parmelee, K.W. The Flag of Portugal in History and Legend. Romanic Rev. 1918, 9, 291.

21. Morujão, M.R.B. A sigilografia portuguesa em tempos de D. Afonso Henriques. Medievalista 2012, 11, 1-28. [CrossRef] 